\title{
Ultrasound Assessment of Cervical Length in the First Trimester of Pregnancy to Predict Preterm Birth
}

\author{
Valery G. Volkov, $\mathrm{PhD}, \mathrm{ScD}^{1 *}$; Olga V. Chursina ${ }^{1,2}$ \\ ${ }^{1}$ Tula State University, ${ }^{2}$ Tula Regional Perinatal Center \\ Tula, the Russian Federation
}

\begin{abstract}
The aim of this study was to examine the potential value of routine measurement of cervical length (CL) in singleton pregnancy at 11 to 14 weeks of gestation for predicting the risk for spontaneous preterm delivery (PD).

Materials and Methods: CL was assessed using transvaginal sonography (TVS) in the gestational period between 11 and 14 week in 1517 women. Childbirth at 22-36 weeks was considered as PD. The control group included pregnant women who gave birth within 37 weeks or more.

Results: The mean age of mothers was $25.3 \pm 4.9$ years (age range of 17 to 43 ). Among them, 846 (55.8\%) women were primiparous and $671(44.2 \%)$ - multiparous. The average CL was $38.9 \pm 4.3 \mathrm{~mm}$ (range of 18 to $49 \mathrm{~mm}$ ). The area under the ROC curve of the corresponding relationship between the CL forecast and the probability of PD occurrence was 0.84 . When selecting the threshold value of the function at the point $35 \mathrm{~mm}$, we predicted a high risk of PD with a sensitivity of $66.2 \%$ and a specificity of $84.2 \%$. At the $C L$ value of $30 \mathrm{~mm}$, the sensitivity of the method was $51.5 \%$, specificity $98.7 \%$. For CL: OR=0.79, $95 \%$ CI: $0.75-$ $0.83 ; P=0.0001$. Thus, the most optimal cut-off $C L$ is the threshold value of $30 \mathrm{~mm}$.

Conclusion: TVS is an objective, reproducible and reliable method for assessing the cervix uteri and can predict the risk of preterm delivery.(International Journal of Biomedicine. 2018;8(4):321-323.)
\end{abstract}

Key Words: singleton pregnancy $\bullet$ cervical length $\bullet$ preterm delivery $\bullet$ transvaginal sonography

\section{Abbreviations}

CL, cervical length; PD, preterm delivery; ROC curve, Receiver Operating Characteristic curve; TVS, transvaginal sonography

\section{Introduction}

Preterm delivery (PD) remains a significant obstetric problem, determining the rate of perinatal mortality.(1) Proven predictors of PD are PD in history, the level of fetal fibronectin, and shortening of cervical length $(\mathrm{CL}){ }^{(2,3)}$ Fibronectin, as a risk marker, is not used in Russia. The study of CL and the search for new markers indicate real prospects for medical interventions. Numerous studies have shown the relationship between $\mathrm{CL}$ in the second trimester of pregnancy (18 to 22 weeks) and $\mathrm{PD}{ }^{(4-7)} \mathrm{CL}<30 \mathrm{~mm}$ is considered critical up to

*Corresponding author: Prof. Valery G.Volkov, PhD, ScD; Tula State University, Tula, Russia.E-mail: valvol@,Yandex.ru
20 weeks, and less than $20 \mathrm{~mm}$ is an absolute criterion of cervical insufficiency in any term. ${ }^{(3,8)}$ Early prevention of PD is associated with progesterone therapy in early pregnancy, which requires the development of criteria for evaluation of $\mathrm{CL}$ in the first trimester. ${ }^{(9,10)}$

The aim of this study was to examine the potential value of routine measurement of CL in singleton pregnancy at 11 to 14 weeks of gestation for predicting the risk for spontaneous PD.

\section{Materials and Methods}

A prospective observational study was conducted in the period from April 1, 2012 to September 30, 2013 in the Tula Regional Perinatal Center as part of a screening program for chromosomal and structural abnormalities. 
Inclusion criteria were 11 to 14 weeks of gestation, singleton pregnancy, and no complaints at the time of examination.

Exclusion criteria were surgical treatment of the cervix, multiple pregnancy, congenital anomalies of the female genital tract, and fetal abnormalities.

Description of medical intervention

The linear dimensions of the cervix were estimated as the distance from the projection of the internal orifice to the projection of the external orifice in sagittal scanning, taking into account the curvature of the cervical canal. Tracing was used to measure the length of the cervical canal.

A total of 1637 women met the inclusion criteria. CL was assessed in the gestational period between 11 and 14 weeks. Out of 1637 women, 112 were lost for follow-up, and 8 women underwent cesarean delivery because of an emergency with the fetus. Therefore, 1517 women were included for further examination. Childbirth at 22-36 weeks was considered as PD. The control group included pregnant women who gave birth within 37 weeks or more. Gestational age was determined by the data of the first day of the last menstrual period and ultrasound data on crown-rump length. TVS was performed using a 7.5-MHz transvaginal probe (MEDISON V20). The study was carried out by the doctor-expert, certified by the Fetal Medicine Foundation for the first trimester screening and $\mathrm{CL}$ assessment.

Statistical analysis was performed using IBM SPSS Statistics for Windows, Version 23.0. Armonk, NY: IBM Corp.). Correlation analysis, nonparametric quantitative data analysis, binary logistic regression with determination of predictive model sensitivity and specificity, and evaluation of diagnostic significance using ROC-curves method were used. A probability value of $P<0.05$ was considered statistically significant.

\section{Results}

The mean age of mothers was $25.3 \pm 4.9$ years (age range of 17 to 43). Among them, 846 (55.8\%) women were primiparous and $671(44.2 \%)$ - multiparous. The average CL was $38.9 \pm 4.3 \mathrm{~mm}$ (range of 18 to $49 \mathrm{~mm}$ ). The data of CL distribution do not follow a normal distribution according to the Kolmogorov-Smirnov normality test (Figure 1).

The correlation analysis showed a correlation between $\mathrm{CL}$ and PD $(r=+0.321)$. The resulting model accounted for $10.3 \%$ of the factors determining changes in the term of labor (Figure 2).

Binary logistic regression with determination of sensitivity and specificity of the prognostic model was used to estimate the probability of PD occurrence depending on the quantitative index of CL. The observed dependence is described by the equation:

$$
\begin{gathered}
p=\frac{1}{1+e^{-z}} \\
z=10.31-0.374^{*} \mathrm{X}
\end{gathered}
$$

where $p$ is the probability of PD occurrence $\mathrm{X}-\mathrm{CL}$ measured in the first trimester of pregnancy $(\mathrm{mm})$ 10.31 - the estimated constant

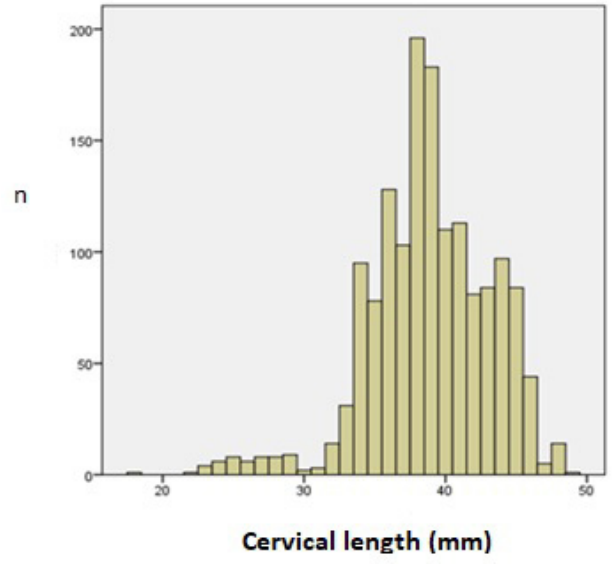

Fig. 1. CL distribution at 11-14 weeks of gestation in 1517 singleton pregnancies.

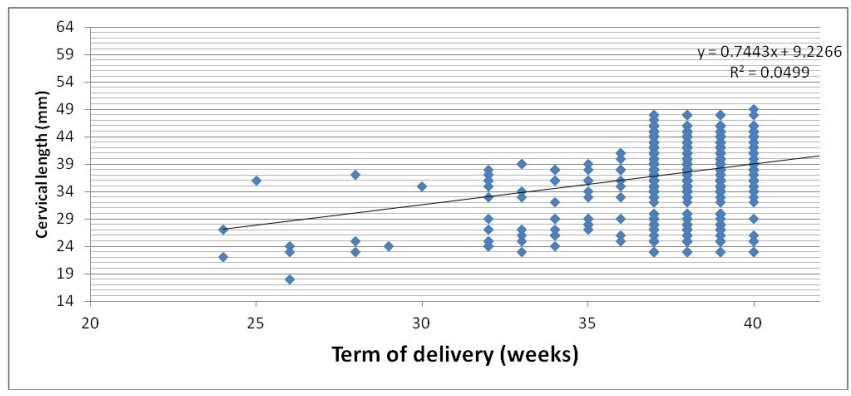

Fig. 2. Dependence of the labor term on $C L$ in the first trimester.

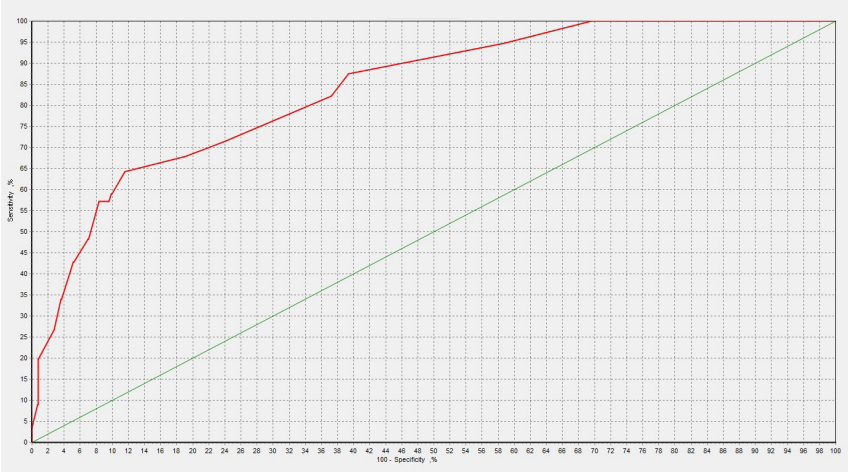

Fig. 3. ROC-analysis: CL index measured in the first trimester of pregnancy for $P D$ prognosis.

Based on the values of regression coefficients, the factor CL, measured in the first trimester of pregnancy, has a feedback with the probability of PD: With a decrease in CL, the probability of delivery before 37 weeks increases.

The resulting regression model is statistically significant $(P<0.001)$. Based on the value of the coefficient of determination (Nagelkerke's $\mathrm{R}^{2}$ ) the model (1) takes into account $39.3 \%$ of the factors determining the probability of PD. This model has a diagnostic efficiency of $96 \%$, specificity of $99.4 \%$, but rather low sensitivity of $38.2 \%$.

Evaluation of diagnostic significance of the CL index measured in the first trimester of pregnancy for PD prognosis was performed by ROC-analysis (Figure 3). 
So, it is necessary to find the optimal separating value CL (cut-off), which allows classification of patients according to the degree of PD risk, which has the best combination of sensitivity and specificity.

The area under the ROC curve of the corresponding relationship between the CL forecast and the probability of PD occurrence was 0.84 . When selecting the threshold value of the function at the point $35 \mathrm{~mm}$, we predicted a high risk of PD with a sensitivity of $66.2 \%$ and a specificity of $84.2 \%$. At the CL value of $30 \mathrm{~mm}$, the sensitivity of the method was $51.5 \%$, specificity 98.7\%. For CL: $\mathrm{OR}=0.79,95 \%$ CI: $0.75-0.83 ; P=0.0001$.

\section{Discussion}

Despite the lack of effective measures to prevent preterm labor, identification of individuals at high risk for PD remains important for gaining an understanding of the various pathophysiological pathways and for assessment of therapeutic efficacy. ${ }^{(11)}$ Although preterm labor can be the result of various causes, ${ }^{(12,13)}$ cervical shortening has consistently been shown to occur prior to the onset of preterm labor. ${ }^{(2,6)}$ The effectiveness of measures aimed at prolongation of pregnancy depends on the obstetric situation, pregnancy term and fetal prognosis. ${ }^{(9)}$ This makes it necessary to identify women at risk for PB as early as possible. TVS is an objective, reproducible and reliable method for assessing the cervix uteri and can predict the risk of PD. ${ }^{(14)}$ Assessment of the cervix enables measurement of CL.

There is an inverse correlation between CL and the date of birth. The high specificity of the method allows us to avoid unnecessary interventions, such as tocolysis or cervical cerclage, in uncomplicated pregnancies. The low sensitivity of the method should be noted: with $\mathrm{CL}=35 \mathrm{~mm}-38.2 \%, \mathrm{CL}=30 \mathrm{~mm}-48.5 \%$, and $\mathrm{CL}=25 \mathrm{~mm}-76.5 \%$. Although, $\mathrm{CL} \leq 25 \mathrm{~mm}$ is associated with a significantly increased frequency of $\mathrm{PD}$, detecting such values in the first trimester of pregnancy is extremely rare. At this time it seems to us that the most optimal cut-off CL is the threshold value of $30 \mathrm{~mm}$. High specificity will exclude women with normal risk, and to offer those who are in the risk zone additional cervicometry in 16 weeks and a subsequent decision on the need for the use or cancellation of progesterone drugs or the transvaginal cervico-isthmic cerclage in uncomplicated pregnancies. To further improve the forecasting model, using the latest knowledge of the development model and potential risk factors, it is necessary to contribute to the personal risk assessment of spontaneous preterm delivery. ${ }^{(15)}$

\section{Conflict of interest}

The authors declare that they have no competing interests.

\section{References}

1. Goldenberg RL, Culhane JF, Iams JD, Romero R. Epidemiology and causes of preterm birth. Lancet. 2008;371(9606):75-84. doi:10.1016/S0140-6736(08)60074-4.

2. Son M, Miller ES. Predicting preterm birth: Cervical length and fetal fibronectin. Semin Perinatol. 2017;41(8):445-
51. doi:10.1053/j.semperi.2017.08.002.

3. Martynenko PG, Volkov VG. [Prediction of preterm labor on the basis of the most significant risk factors]. Akush Ginekol (Mosk). 2012;1:103-7. [Article in Russian].

4. Crane JM, Hutchens D. Transvaginal sonographic measurement of cervical length to predict preterm birth in asymptomatic women at increased risk: a systematic review. Ultrasound Obstet Gynecol. 2008;31:579-87 doi: 10.1002/ uog. 5323

5. Martynenko PG, Volkov VG, Zaikina FY, Kuzmina IV, Loginova TA. [New aspects of the prevention of premature delivery among women with symptoms of threatened abortion]. J New Med Tech. 2010;17(4):151-3. [Article in Russian].

6. Berghella V, Baxter JK, Hendrix NW. Cervical assessment by ultrasound for preventing preterm delivery. Cochrane Database Syst Rev. 2013;31(1):CD007235. doi: 10.1002/14651858.CD007235.pub3.

7. Bohîlțea RE, Munteanu O, Turcan N, Baros A, Bodean O, Voicu D, et al. A debate about ultrasound and anatomic aspects of the cervix in spontaneous preterm birth. J Med Life. 2016;9(4):342-7.

8. Volkov VG, Zaikina FY, Kultygina SV. Modern approaches to the prediction of occurrence of preterm birth. J New Med Tech. 2009;16(4):112-3. [Article in Russian].

9. Romero R, Nicolaides K, Conde-Agudelo A, Tabor A, O'Brien JM, Cetingoz E, et al. Vaginal progesterone in women with an asymptomatic sonographic short cervix in the midtrimester decreases preterm delivery and neonatal morbidity: a systematic review and metaanalysis of individual patient data. Am J Obstet Gynecol. 2012;206(2):124.e1-19. doi.org/10.1016/j.ajog.2011.12.003

10. Hassan SS, Romero R, Vidyadhari D, Fusey S, Baxter JK, Khandelwal $\mathrm{M}$, et al. Vaginal progesterone reduces the rate of preterm birth in women with a sonographic short cervix: a multicenter, randomized, double-blind, placebo-controlled trial. Ultrasound Obstet Gynecol. 2011;38(1):18-31. doi: 10.1002/uog.9017.

11. Greco E, Lange A, Ushakov F, Calvo JR, Nicolaides KH. Prediction of spontaneous preterm delivery from endocervical length at 11 to 13 weeks. Prenat Diagn. 2011;31(1):84-9. doi: 10.1002/pd.2640.

12. Akhilgova ZS. [Periodontitis diseases and premature parturition (literature review)]. J New Med Tech, eEdition. 2018;1:15(7-5). doi: 10.24411/2075-4094-2018-15982. [Article in Russian].

13. Markovskaya TV, Michalevich SI, Yakutovskaya SL, Mardas AV, Markovskaya KS. [Possibilities of modern obstetrics at premature birth]. Med Novosti. 2015;2:11-6. [Article in Russian].

14. Lim K, Butt K, Crane JM; DIAGNOSTIC IMAGING COMMITTEE; FAMILY PHYSICIANS ADVISORY COMMITTEE; MATERNAL FETAL MEDICINE COMMITTEE. SOGC Clinical Practice Guideline. Ultrasonographic cervical length assessment in predicting preterm birth in singleton pregnancies. J Obstet Gynaecol Can. 2011;33(5):486-499. doi: 10.1016/S1701-2163(16)34884-8.

15. Meertens LJE, van Montfort P, Scheepers HCJ, van Kuijk SMJ, Aardenburg R, Langenveld J, et al. Prediction models for the risk of spontaneous preterm birth based on maternal characteristics: a systematic review and independent external validation. Acta Obstet Gynecol Scand. 2018;97(8):907-920. doi:10.1111/aogs.13358. 